\title{
Development of a radioecological risk assessment tool for the Toulon marine area
}

\author{
C. Duffa ${ }^{1}$, H. Thebault ${ }^{1}$, S. Coudray ${ }^{2}$, S. Charmasson ${ }^{1}$ \\ \& M. Arnaud ${ }^{1}$ \\ ${ }^{I} I R S N$, France \\ ${ }^{2}$ IFREMER, France
}

\begin{abstract}
Toulon naval base, located on the Mediterranean coast, is the first French military harbour. As it receives nuclear power ships, any possibility of accidental release of radionuclides is to be considered. To estimate post-accidental consequences in the marine environment and to propose adapted management plans, data concerning both radionuclides spatial dispersion and environmental sensitivity to this contamination are necessary. The French Institute for Radioprotection and Nuclear Safety (IRSN) developed an integrated tool to support experts and decision makers in post-accidental situations concerning this area. This management tool aims to combine radionuclides dispersion modelling and radioecological sensitivity local maps to outline vulnerable areas in advance of a known release. The calculation of radionuclides dispersion is based on an existing hydrodynamic model (MARS 3D developed by IFREMER). Data concerning local bathymetry, sedimentology and climatic conditions are necessary to build a model with a good resolution $(100 \mathrm{~m}$ grid). The radioecological sensitivity of the marine environment is estimated and mapped after a specific study. The studied area is divided into several unit zones, for which a sensitivity index will be attributed. Sensitivity is determined by the relationship between different factors: the ecosystem intrinsic characteristics (physical or biological), the radioecological parameters (dependant of the concerned radionuclide) and the socio-economical resources. Values are attributed to these factors regarding their efficiency to increase or decrease the final sensibility. Their combination results in a sensitivity index that is reported in a geographical information system (GIS). The development of such a management tool requires an important data collection step. The results are based on the local environment characterization.
\end{abstract}

Keywords: radioactive pollution, post-accidental management, marine environment, vulnerability. 


\section{Introduction}

The first French military harbour is located on the Mediterranean French coast, in Toulon (Figure 1). It receives several nuclear-powered submarines and one aircraft carrier. For this reason, any potential accidental radionuclide release into the environment is to be considered here. The qualification, quantification and the evaluation of the consequences of the contamination of the marine environment either due to a direct discharge or after an atmospheric dispersion would be essential to assess such a situation.

We propose to develop a specific tool to contribute to this evaluation and to help experts and stakeholders to manage the post-accidental situation: contaminated areas localisation and contamination levels, vulnerability of these areas for considered radionuclides, environmental and economical consequences.

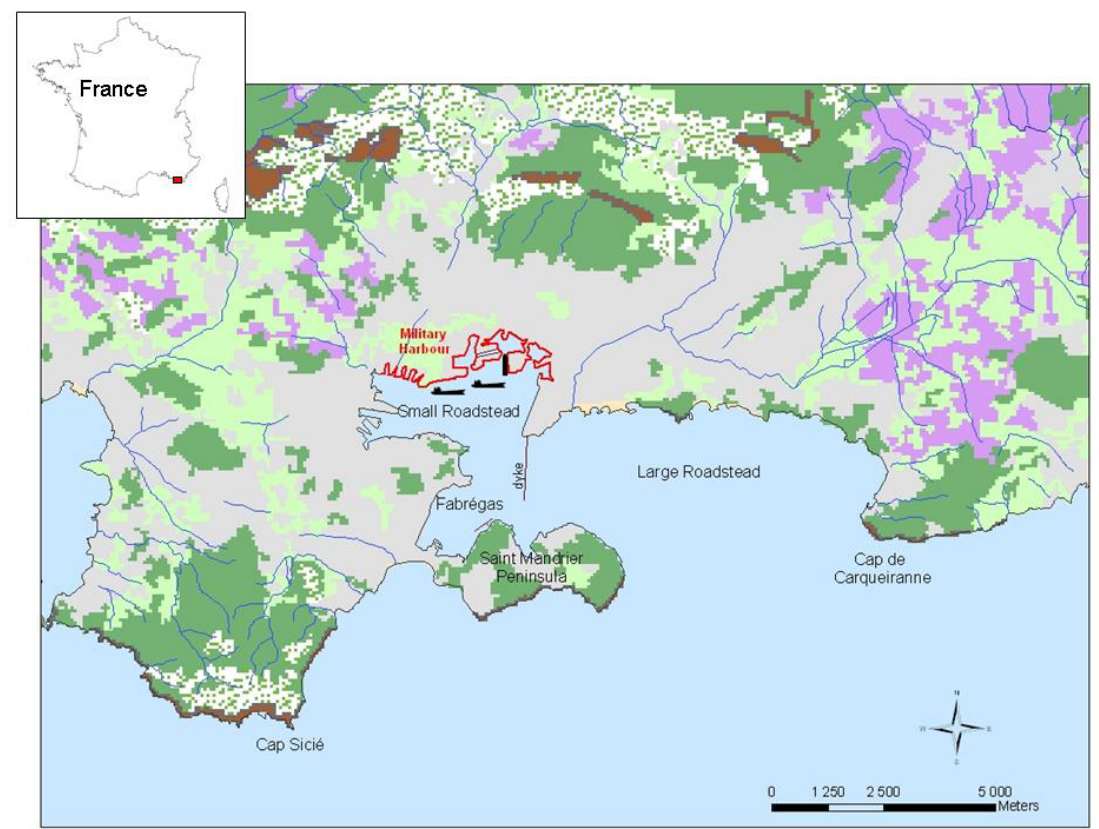

Figure 1: $\quad$ Location of the studied area in the south of France.

\section{Methodology}

We propose to develop at the same time two complementary tools: a hydrodynamic model usable to predict radionuclide dispersion after an accidental discharge, and an atlas of radioecological sensitivity maps for the studied area. The discharge characterization (risk factor) and the radionuclide dispersion modelling (the pollution vector considered as a first approach is the sea water) are combining to predict contaminated areas. A radioecological sensitivity study 
that requires sensitivity factors characterization and codification, and their combination to attribute sensitivity indices will allow identification of the most sensitive areas. As proposed by Denis [1], we define vulnerable areas by combining contaminated area mapping and radioecological sensitivity maps (Figure 2).

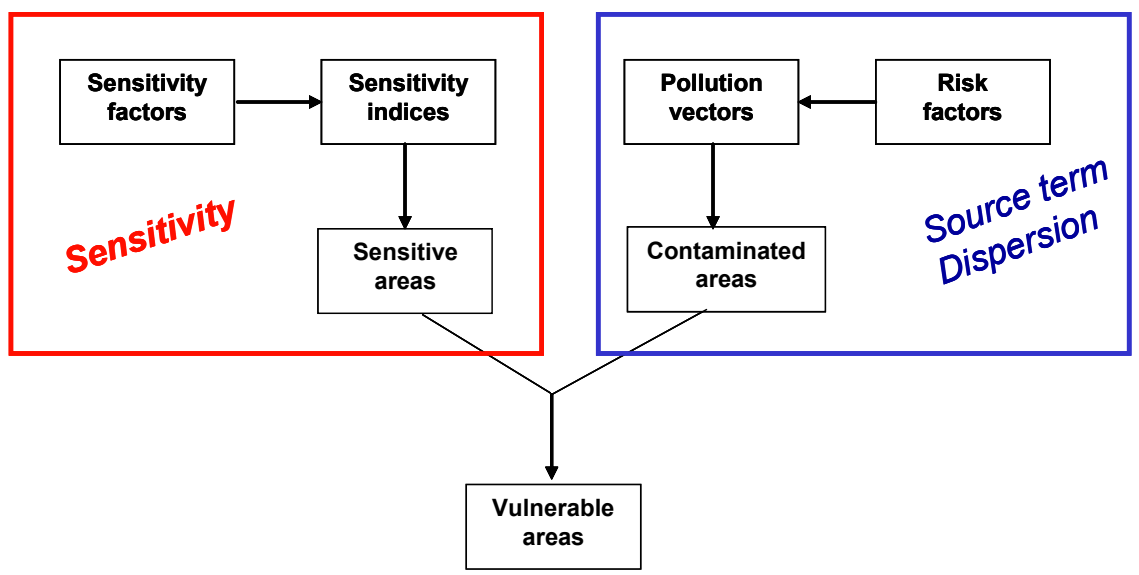

Figure 2: $\quad$ Methodology to characterize vulnerable areas (adapted from Denis [1]).

For any post-accidental situation, the assessment of the radioecological state must take into account the pre-accidental situation. Moreover, activity levels and radionuclides distribution in the environment reflect environmental capacity to accumulate or not the radionuclides. For these reasons, the baseline radioecological state of this marine area has to be evaluated.

\section{Background radioecological state}

Some artificial radionuclide activities have been measured in this area since 2000 by IRSN, mainly in surface sediments that accumulated past global inputs (nuclear tests and Chernobyl atmospheric depositions). ${ }^{137} \mathrm{Cs}$ gamma measurement results are in the range DL $-13 \mathrm{~Bq} \cdot \mathrm{kg}^{-1}$ dry weight. The highest activities are measured in the small roadstead where sediments are the finest. ${ }^{238} \mathrm{Pu},{ }^{239+240} \mathrm{Pu}$ and ${ }^{241} \mathrm{Am}$ measured by alpha counting provide the same observation and attest the origin of this background contamination. These results suggest that the small roadstead could be qualified as a sensitive area for its capacity to trap some radionuclides in the sediment compartment.

Radionuclide activities are too low to be measured in seawater. Mussels, used as bioindicators, allow an indirect evaluation of the water ${ }^{137} \mathrm{Cs}$ activity. It is estimated to be about $1 \mathrm{~Bq} \cdot \mathrm{m}^{-3}$. 


\section{Accidental contamination characterization}

Location and characterization of contaminated areas depends both on the source term itself and on its dispersion in the local marine environment.

\subsection{Source term}

Different accidental scenarios could be defined. The core fusion of any generator with the environmental release of a large spectrum of radionuclides is the most conservative scenario. The radionuclide input into the marine environment could be direct, such as a shipwreck, or indirect through an atmospheric deposition onto the sea surface after an atmospheric discharge. It is also possible to consider an indirect input through the weathering of contaminated soils in the Toulon catchment area.

As the first stage of this project, the considered radionuclides are ${ }^{137} \mathrm{Cs},{ }^{60} \mathrm{Co}$, ${ }^{239} \mathrm{Pu}$ and ${ }^{3} \mathrm{H}$. These are included in the radioactive discharge due to the fusion scenario, and present different environmental behaviours that would be interesting to compare in such an application.

\subsection{Marine dispersion modelling}

Radionuclides dispersion is evaluated by modelling. This modelling requires the use of a hydrodynamic model that could be coupled with a sedimentary module when it is necessary to consider contaminated sediments dispersion (for reactive radionuclides such as $\mathrm{Pu}$ for instance).

For hydrodynamic modelling, we use the code MARS 3D (Lazure and Dumas [2]) developed by IFREMER (French Research Institute for Exploitation of the Sea). This model is dedicated to applications at regional and local scales. To reproduce local small scale hydrological features, it is necessary to provide results with a good resolution. This resolution depends on the model grid size, which is compelled by input data precision (bathymetry, boundary conditions given by a larger scale model, and meteorological data).

The local bathymetric model is obtained using the maximum of data available (Hydrological and Oceanographic Service of the French Navy SHOM measurements completed with some direct measurements carried out for this study). Boundary conditions are given by a larger scale model that covers the French Mediterranean Eastern coast (grid size $=400 \mathrm{~m}$ ), which is a sub-model of the North Western Mediterranean Sea model (grid size $=1200 \mathrm{~m}$ ). Meteorological data are given by Météo-France.

With these data, we define a $100 \mathrm{~m}$ grid size model including the Toulon marine area. For each grid mesh, $\vec{u}$ and $\vec{v}$ horizontal components of the current, salinity and temperature are calculated for 30 vertical sigma layers. Boundary conditions, but especially wind direction and intensity will be responsible for the resulting currents. The radionuclide dispersion results are based on these calculated currents. 
An example of the hydrodynamic simulation result is given in Figure 3 for realistic meteorological conditions. In post-accidental conditions, the forecasting meteorological conditions would be used. Nevertheless, it is interesting to have different defined meteorological scenarios (local specific scenarios are: Mistral (NW) intense wind with no rain, East wind with rain, and no wind conditions) to provide contamination maps that can be used to define environmental sampling plans in this area.

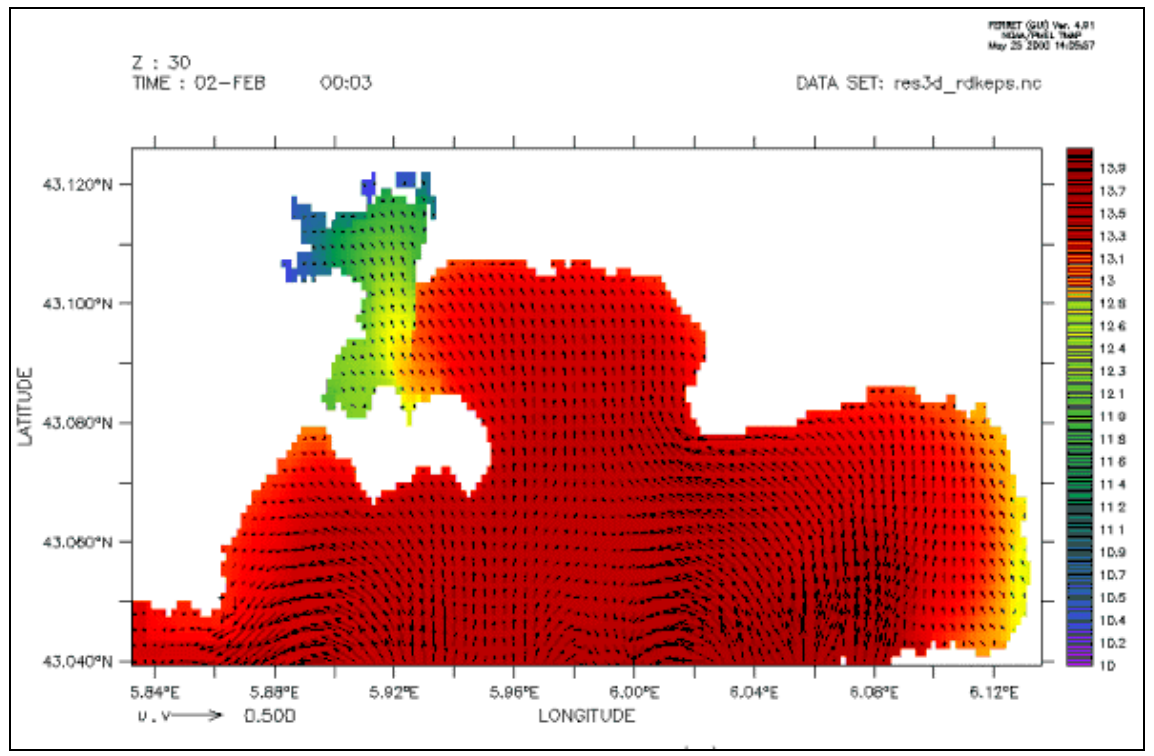

Figure 3: $\quad$ Example of calculated surface current $\left(\mathrm{m} \cdot \mathrm{s}^{-1}\right)$ and temperature $\left({ }^{\circ} \mathrm{C}\right)$.

\section{Radioecological sensitivity assessment}

The radioecological sensitivity of the environment is studied by the IRSN in atmospheric, terrestrial and marine compartments. The basic concept has been presented by Mercat-Rommens et al. [3]. An adaptation is proposed, taking into account marine environment specificities and based on existing approaches developed for the oil spill pollution domain. Since the 1980s mapping of the coastal vulnerability to oil spill pollution has been developed in the United States on the basis of attribution of the Environmental Sensitivity Index (ESI) (NOAA [4]). Their values are attributed mainly considering shoreline characteristics (slope, exposure to waves, substrate type) that determine the possible persistence of oil and ease of cleanup. More recently, biological and economical aspects have been included in this analysis. This kind of map has been proposed by the Regional Marine Pollution Emergency Response Centre for the Mediterranean Sea (REMPEC) as a demonstrator for the North-Western Mediterranean Sea.

Then, the following iterative methodology was chosen to obtain radioecological sensitivity maps (Duffa et al. [5]): 
- division of the studied area into several homogeneous unit zones;

- identification of and characterization of parameters acting as sensitivity factors;

- $\quad$ sensitivity factors aggregation giving a global sensitivity index for each unit zone;

- results representation and mapping.

\subsection{Homogeneous zoning areas}

This step goal is to divide the entire studied area (the Toulon marine area) into homogeneous and coherent zones regarding their environmental states and uses. Of course, the unit zone size has to be coherent with the dispersion modelling scale (calculation grid). Finally, a unique sensitivity index will be attributed for each defined sector.

\subsection{Sensitivity factors}

Two kinds of parameters are considered as sensitivity factors:

- Physical and biological parameters, it is to say the intrinsic characteristics of the environment. In these criteria, we include shoreline shape, substrate type (as grain size), biocenotic characteristics with inventories of animal and vegetal species and their densities. The presence of rare species is also important.

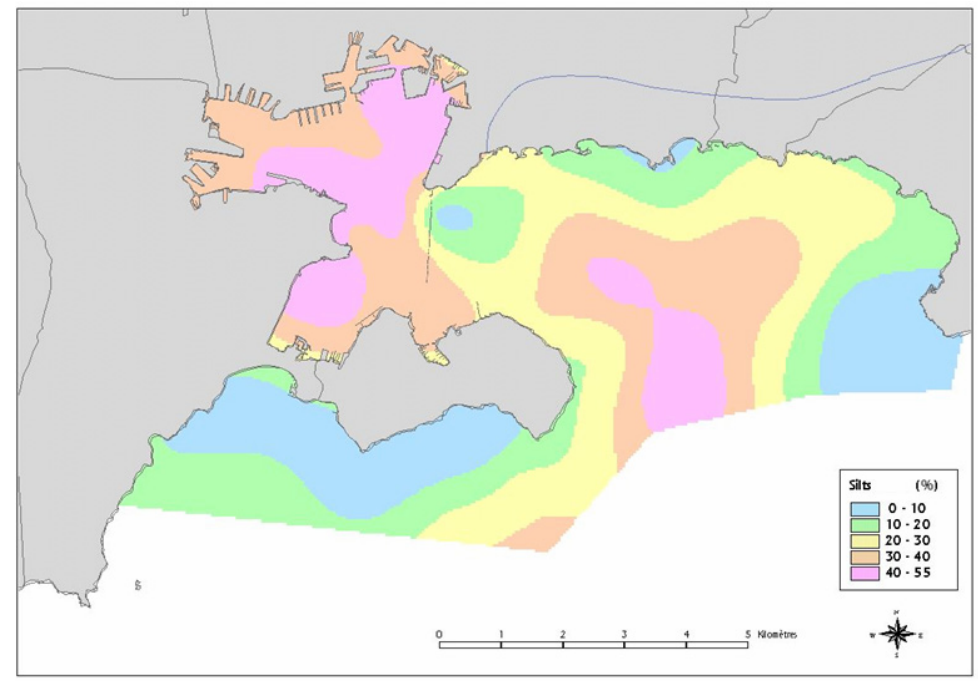

Figure 4: Silts distribution in surface sediments of the Toulon marine area.

These data are mostly available thanks to past studies. Surface sediment size distribution was evaluated in 2000 by IRSN when studying the radiology of this area. These results suggest that the small roadsteads, as well as the central channel in the large raodstead, when the portion of small grain size sediments is the highest, are much more sensitive for reactive radionuclides trapping. 
Biocenotic distribution has been studied and mapped in this area for a local specific integrated study (SIAT [6]). The western part of the studied area, along the rock coast, is qualified as the richest zone. The small roadstead is opposite, qualified as poor from this ecological point of view.

- The second criterion concerns resources and uses, and refers to professional or recreational activities, like fishing, aquaculture that concerns fish or mussels, possible water intake or tourist activities on beaches. Protected or classified areas must also be taken into account in this section. These data have been partially inventoried by the "Syndicat Intercommunal de l'Aire Toulonnaise" (SIAT [6]), but need to be completed. Moreover, the indicators that are retained to qualify and quantify the sensitivity of these factors have to be defined.

For all these parameters, a codification is decided. A value is attributed to each of them regarding their capacity to increase or decrease the global sensitivity indicator. That can be binary values (for the presence or not of rare species for instance) or entire values (on a 0-3 scale).

\subsection{Sensitivity index}

The sensitivity index calculation appears to be the crucial step. It results from the combination of sensitivity factors that are weighted regarding their relative importance.

At this stage, we have to introduce the radioecological specificity of this approach. Weights attributed to each sensitivity factor depend on the considered radionuclide. Therefore, they are also based on the values of radioecological parameters (e.g. concentration factors expressing the transfer to biological species, partitioning coefficients $(\mathrm{Kd})$ expressing distribution between liquid and solid phases).

\subsection{Results representation}

Results obtained throughout the study are reported on thematic maps (Figure 5), using a management sub-system based on the use of a GIS (Geographical Information System).

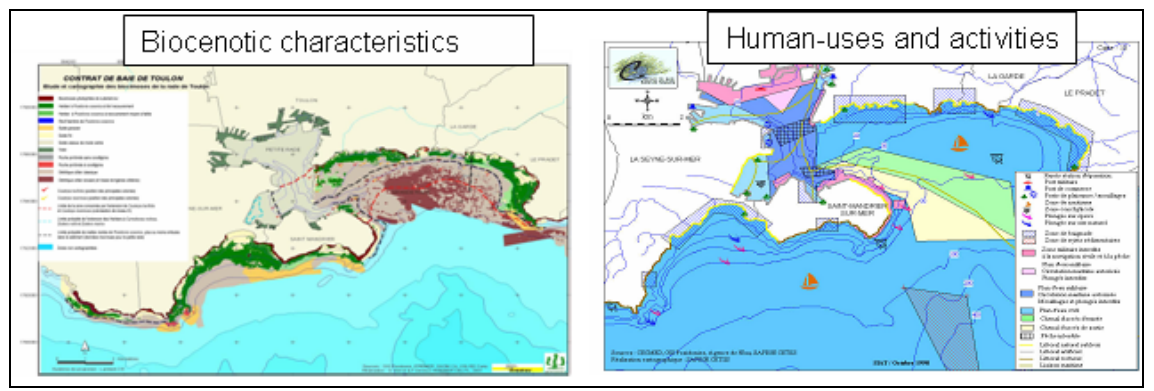

Figure 5: $\quad$ Examples of thematic maps (sensitivity factors). 
The GIS is also usable to build decision trees (using the Model Builder tool) as a first approach to provide resulting maps.

\section{Conclusion}

The Toulon marine area includes the first french military harbour. Since nuclear powered ships are based and repaired here, it is necessary to consider any accidental risk. IRSN developed a specific tool dedicated to helping experts and decision makers to evaluate consequences of any accidental contamination of the marine environment. This project is based on the development of a radionuclide dispersion forecasting model coupled with a radioecological sensitivity study of this marine area. It will allow characterization of vulnerable areas for any defined accident.

\section{References}

[1] Denis J., 1997, Développement et validation de méthodes de classification de la zone côtière, une contribution à sa gestion intégrée, $\mathrm{PhD}$, Paul Sabatier University (Toulouse III).

[2] Lazure P. and Dumas F., 2008, An external-internal mode coupling for a 3D hydrodynamical model for applications at regional scale (MARS), Advances in Water Resources, Volume 31, Issue 2, Pages 233-250.

[3] Mercat-Rommens C., Roussel-Debet S., Briand B., Durand V., Besson B., Renaud P., The radioecological sensitivity of territories: towards an operational tool through the SENSIB Project, Radioprotection, 42, pp. 277295, 2007.

[4] NOAA (National Oceanic and atmospheric Administration), 2002, Environmental Sensitivity Index Guidelines, NOAA Technical Memorandum NOS OR\&R 11.

[5] Duffa C., Mercat-Rommens C., Thébault H., 2007, Radioecological sensitivity project on the French Mediterranean coastal environment, 38th CIESM congress, 09-13 April 2007, Istanbul.

[6] SIAT, 1998, Contrat de baie Rade de Toulon - Dossier préalable, Rapport du Syndicat Intercommunal de l'Aire Toulonnaise, 210 pp. 